\title{
EN TORNO A LA REFORMA ELECTORAL: ENTRE PENDIENTES LEGISLATIVOS Y CASOS PARA CONTRARREFORMA
}

\author{
Jorge Armando Rodríguez Vélez ${ }^{1}$
}

\begin{abstract}
RESUMEN
Se aborda el recorrido que ha tenido la reforma electoral en el Perú en los últimos años y la participación del Jurado Nacional de Elecciones en su desarrollo, así como los temas que deberían ocupar parte primordial del debate y otros que pueden ser materia de contrarreforma.
\end{abstract}

\section{PALABRAS CLAVE}

Jurado Nacional de Elecciones, infracción, reforma electoral.

\section{ABSTRACT}

The course of the electoral reform in Peru in recent years and the participation of the National Elections Board in its development, as well as the topics that should occupy a fundamental part of the debate and others and can be a matter of counter-reform, are discussed.

\section{KEY WORDS}

National Elections Jury, infraction, electoral reform.

\section{EN TORNO A LA REFORMA ELECTORAL: ENTRE PENDIEN- TES LEGISLATIVOS Y CASOS PARA CONTRARREFORMA}

\section{Introducción}

Durante los últimos años hemos sido testigos de la difícil travesía que ha significado emprender reformas en materia electoral en nuestro país. Así, hemos visto cómo temas medulares de la reforma han sido constantemente postergados dejando paso solo a modificaciones legislativas coyunturales, que no han solucionado los problemas de fondo, generando con ello que la reforma electoral sea vista como uno de nuestros eternos pendientes legislativos, hecho cuya gravedad e importancia solo advertimos cada cuatro o cinco años en que la ciuda- danía es convocada a las urnas para los procesos electorales de mayor envergadura.

En los últimos años, el Jurado Nacional de Elecciones ha venido proponiendo diversos proyectos de ley sobre la materia, siendo su más reciente aporte el proyecto de ley de Código Electoral, presentado el 26 de abril de 2017, que es una iniciativa que busca alcanzar

Miembro Titular del Pleno del Jurado Nacional de Elecciones. Abogado, Magíster en Derecho con especialidad en Ciencias Penales por la USMP, Doctor en Derecho por la UAP, Ph. D. con especialización en estudios legales por la Atlantic International University. Acreditador Internacional por IIDEA A.C. y CONFEDE A.C. México para la Acreditación de Educación Superior en Derecho - 2013. Doctor Honoris Causa por la Universidad Peruana de Las Américas (2014), por la Universidad Nacional de Piura (2016), y por la Universidad José Carlos Mariátegui (2017). Docente en la USMP y de postgrado en la Universidad Nacional de Piura. Autor de Reforma y contrarreforma electoral: Apuntes para el debate, El Método Jurídico Penal, Manual de Derecho Penal, entre otras publicaciones. 
una integración coherente del marco legal electoral peruano, con el objetivo de promover el fortalecimiento de los partidos políticos, la idoneidad de los candidatos a cargos de elecciones populares y de lograr una mejor gestión de los procesos electorales.

En agosto de 2016, el Congreso de la República dispuso la conformación de un grupo de trabajo parlamentario encargado del estudio de la Reforma Electoral. Esta subcomisión presentó el 12 de mayo su informe final como resultado del análisis de diversos proyectos de ley presentados sobre la materia, incluyendo en el análisis de algunos temas las propuestas del proyecto de ley de Código Electoral del Jurado Nacional de Elecciones, siendo aprobado dicho informe el 16 de mayo, y siendo adoptado el referido informe como un insumo para el debate.

Asimismo, la Comisión de Constitución del Congreso de la República acordó realizar el debate de la reforma electoral en base a temas puntuales y no de forma integral, por lo que, antes de finalizar el presente año, se espera ver la aprobación de modificaciones legislativas en temas tales como cronograma electoral, financiamiento político, e impedimentos para postular, siendo que, del primero de estos temas ya se aprobó un dictamen el pasado 13 de junio.

En esa medida, estando a escasos meses para la convocatoria a uno de los procesos electorales más importantes en nuestro país, como las
Elecciones Regionales y Municipales 2018, resulta urgente que la Comisión de Constitución del Congreso de la República priorice el debate de la reforma electoral, y de los proyectos como el Código Electoral presentado por el Jurado Nacional de Elecciones, a fin de que, fuera de los temas puntuales a modificarse próximamente, se aborden más adelante, con mayor detenimiento, los temas medulares para una más completa reforma electoral.

\section{Temas relevantes de una re- forma aún pendiente}

\section{Dispersión de la normativa electoral}

Como primer punto considero que es necesario retomar el camino de una reforma electoral integral, que apunte hacia una integración coherente del marco legal electoral peruano.

Una medida que se propone para tal fin desde el Jurado Nacional de Elecciones, y que fue compartida por la subcomisión encargada del estudio de la Reforma Electoral al interior de la Comisión de Constitución del Congreso de la República, fue la de reemplazar las 17 leyes electorales que conforman el marco legal electoral peruano, por un Código Electoral que sistematice la legislación dispersa, corrigiendo en el camino los vacíos o contradicciones que pudieran existir en dichas normas.

Intangibilidad del marco electoral

Al respecto, cabe recordar que el proceso de Elecciones
Generales 2016 no ha sido el único proceso electoral en el que se modificaron leyes en pleno desarrollo del proceso o una vez convocado el mismo (Ley $N^{\circ}$ 30414), ya que la misma situación se verificó durante las Elecciones Municipales Complementarias 2015 con la aprobación de la Ley $N^{\circ}$ 30305, y en la elección de consejeros del Consejo Nacional de la Magistratura del año 2010 con la aprobación de la Ley N. 29521.

La modificación del marco electoral que atañe a un proceso electoral no puede modificarse una vez que este ha sido convocado, e incluso, no debería modificarse faltando pocos meses para su convocatoria, sin correr el riesgo de perturbar o impedir su desarrollo, o mucho peor, de generar desconfianza en la ciudadanía y participantes. Tal peligro además subsiste en tanto no se adopten medidas que aseguren la estabilidad del marco legal electoral, obligando a que toda reforma se discuta e implemente con la debida anticipación, lo cual permita a la ciudadanía y a las organizaciones políticas conocer la nueva normativa a fondo.

El Proyecto de Ley $\mathrm{N}^{\circ}$ 242/2016-JNE, presentado al Congreso de la República, el 7 de setiembre de 2016, recoge tales inquietudes y propone que se impida la introducción de reformas legales desde un año antes del acto electoral o durante el desarrollo del proceso electoral que se busca normar, a fin de asegurar la intangibilidad del marco legal de los procesos electorales. 


\section{Fortalecimiento de la demo- cracia interna de las organi- zaciones políticas}

El artículo 35 de la Constitución Política señala que las organizaciones políticas contribuyen a la formación y manifestación de la voluntad popular, pudiendo los ciudadanos ejercer sus derechos políticos a través de estas organizaciones.

Ello significa que las organizaciones políticas constituyen mecanismos oficiales de participación ciudadana en la vida política, y es por ello que resulta de vital importancia asegurar que tales organizaciones funcionen con arreglo a la Constitución y las leyes, para una efectiva consecución de sus fines.

Es así que, existe consenso en señalar que la institucionalización y fortalecimiento de las organizaciones políticas debe necesariamente contemplar, a su vez, el fortalecimiento de su democracia interna, lo cual solo puede lograrse a través de la observancia de mecanismos democráticos en su interior, que garanticen el respeto a los derechos de sus afiliados y candidatos, a fin de que la ciudadanía las asuma como verdaderos canales de participación y que las listas y fórmulas electorales que presenten respondan realmente a las necesidades y pedidos ciudadanos.

En esa medida, considero que la reforma electoral debe contemplar algunos puntos que son fundamentales para el fortalecimiento de la democracia interna:
- Intervención obligatoria de los organismos del sistema electoral en las elecciones internas de las organizaciones políticas. La constitución de organizaciones políticas más sólidas y representativas requieren de procesos internos democráticos, y para ello es necesaria la participación obligatoria de los organismos electorales en sus elecciones internas. La propuesta del Código Electoral contempla que el RENIEC se encargue de la elaboración de los padrones electorales, la ONPE de la organización del proceso electoral en simultáneo y el JNE de la fiscalización y resolución de las controversias que puedan suscitarse en tales actos.

\section{- Voto universal y directo} de afiliados. Planteamos, a su vez, que en las elecciones internas de las organizaciones políticas se instaure como única modalidad de elección el mecanismo de voto universal y directo de los afiliados, conocido como "un militante un voto". Adicionalmente a ello, considero personalmente que el debate de esta propuesta debe contemplar también la alternativa de que no solo los militantes o afiliados puedan votar, como es usual en muchos de los países de la región. Así, la ley podría permitir a las organizaciones políticas decidir su sistema de elección interna respecto a este punto, pudiendo realizarse elecciones solo con voto de militantes o con el voto de militantes y de adherentes, con la consiguiente creación de padrones de adherentes para mejor control de tal medida.

- La paridad de género en las listas de candidatos a Congresistas de la República y representantes al Parlamento Andino, consejeros regionales titulares y suplentes, y regidores. El Proyecto de Código Electoral conviene en sustentar la necesidad de que las listas de candidatos deben estar compuestas por $50 \%$ de mujeres y hombres, alternándose entre mujeres y hombres hasta agotar el equivalente de tal porcentaje, a fin de incrementar la participación de las mujeres en política, lo cual no obsta a que se adopte también como una medida progresiva y temporal, pudiendo desactivarse progresivamente, de alcanzarse los objetivos propuestos.

- Paridad de género en órganos directivos de las organizaciones políticas. Igualmente, en línea con lo señalado, personalmente considero que el debate de la reforma electoral también debe contemplar replicar el establecimiento de la paridad de género en otros niveles de participación política, como es el caso de los órganos directivos de los partidos políticos, los cuales también son llamados a reflejar condiciones de igualdad y diversidad en su representación. En tal medida, resultaría conveniente establecer la 
paridad de género al interior de los partidos políticos, esto es, en sus procesos de democracia interna para la elección de sus propias autoridades, a fin de que los órganos directivos del partido muestren paridad de género en su conformación.

- Establecimiento de una fecha fija para las elecciones internas.Complementando la propuesta de intervención obligatoria de los organismos del sistema electoral en las elecciones internas de las organizaciones políticas, el proyecto sostiene la necesidad de que las elecciones internas de las organizaciones políticas se realicen en una sola fecha y en simultáneo, para un mejor control y asesoramiento durante tales procesos.

\section{Especialización de la justicia electoral de primera instan- cia}

Como sabemos, los Jurados Electorales Especiales son órganos de carácter temporal conformados para un proceso electoral específico, y se constituyen por un colegiado conformado de tres miembros: un juez superior titular, que lo preside, un fiscal superior, y un ciudadano designado por sorteo.

Entre las principales labores asignadas a los Jurados Electorales Especiales, se encuentra la de impartir justicia electoral en primera instancia, calificar las solicitudes de inscripción de listas de candidatos, resolver tachas, inscribir can- didaturas, resolver expedientes sobre publicidad estatal, propaganda electoral, neutralidad, y pedidos de nulidad de elección.

Es por ello que sigue siendo una propuesta vigente y necesaria la creación de órganos permanentes para ejercer las labores asignadas a los Jurados Electorales Especiales, a los cuales denominamos Jurados Electorales Descentralizados, como órganos jurisdiccionales permanentes de primera instancia, y que serían integrados por jueces, fiscales y abogados, a fin de alcanzar una mayor nivel de especialización en el primer nivel de la justicia electoral.

Financiamiento privado con mayor control de aportes

Que los aportes por persona natural o jurídica no excedan de las 200 unidades impositivas tributarias, que todo aporte no declarado se presuma de fuente prohibida, que todo aporte sea canalizado a través del sistema financiero, y que en caso de no informar oportuna o debidamente al órgano competente sobre el estado de los aportes, se agraven las sanciones, desde multas hasta la suspensión y posterior cancelación de la inscripción de la organización política.

\section{Eliminación del voto prefe- rencial}

Si bien esta propuesta no ha sido directamente abordada en el proyecto de ley de Código Electoral, personalmente considero que la eliminación del voto preferencial y el pase a un sistema de listas cerradas y bloqueadas, es un paso necesario para el fortalecimiento de los partidos políticos, al garantizarse el respeto de la prelación de las listas de candidatos que resulten de las elecciones democráticas llevadas a cabo dentro de los partidos políticos, y en dicha medida, su aprobación solo tendría sentido de garantizarse, a su vez, que las elecciones internas sean resultado directo de procesos democráticos, lo cual planteamos lograr a través de la intervención obligatoria del JNE, la ONPE y el RENIEC en dichos procesos.

El voto preferencial apareció en una época en que la regulación sobre organizaciones políticas era mínima y comprendía solo temas generales relacionados a los requisitos para alcanzar la inscripción en el registro de partidos políticos, pero siendo que desde el año 2003 en que se publicó la Ley $\mathrm{N}^{\circ}$ 28094, Ley de Partidos Políticos (ahora Ley de Organizaciones Políticas), contamos con normativa especializada que establece la obligatoriedad de la democracia interna para la conformación de las fórmulas y listas de candidatos, ya no resulta coherente el mantenimiento del mecanismo de voto preferencial, y por el contrario, su permanencia puede socavar gravemente la solidez de los partidos políticos.

Entre los principales peligros de mantener este sistema encontramos que el mismo genera una incesante pugna de los candidatos por la notoriedad, haciendo que la propaganda política individual cobre relieve, en menoscabo de la propa- 
ganda orientada a dar conocer la línea programática del partido y su plan de gobierno, llegándose muchas veces a promesas demagógicas y alejadas del programa partidario, o que nada tienen que ver con las prerrogativas de los cargos a los que aspiran.

\section{Entrega de dádivas en cam- paña electoral}

Sobre este punto, considero que urge evaluar el actual tratamiento de esta infracción, creada por Ley $\mathrm{N}^{\circ} 30414$, según la cual se incorporó el artículo 42 en la Ley $N^{\circ}$ 28094, Ley de Organizaciones Políticas -LOP para sancionar con la exclusión a los candidatos involucrados en actos de entrega de dádivas, promesas u ofrecimiento de dinero y regalos en las campañas electorales, siendo necesaria una contrarreforma sobre el particular.

Elecciones Generales 2016, primer proceso en el cual se aplicó dicha normativa, dio como resultado 96 procesos relacionados a esta infracción, y tres candidatos excluidos de la contienda electoral, de un escenario de 2509 candidatos. De ahí que las proyecciones para el próximo proceso de Elecciones Regionales y Municipales 2018, donde se espera tener más de 115 mil candidatos, no sean muy alentadoras para la fiscalización y sanción de dichos actos, los cuales podrían llegar a 4 mil casos de denuncias a tramitarse por los Jurados Electorales Especiales y el Jurado Nacional de Elecciones, en apelación, lo cual podría requerir de más de 1400 horas de audiencias pú- blicas, equivalente a 175 días de trabajo dedicados exclusivamente a escuchar informes orales durante un mínimo de 8 horas diarias.

Es por esto, que considero conveniente que la reforma electoral contemple la modificación de dicha normativa, en atención al posible impacto que podría tener para futuros procesos más complejos, y a tal respecto el proyecto de Código Electoral propone sancionar con una multa entre 10 y 100 UIT la entrega, promesa u ofrecimiento de dinero, regalos, dádivas u otros obsequios de naturaleza económica, o la entrega de propaganda electoral que supere el $0.5 \%$ de la UIT por cada bien entregado, estableciendo gradualidad en la determinación de la sanción en función de la gravedad del hecho imputado determinada por el alcance de la conducta y/o de la propaganda. Asimismo, se propone que el candidato infractor responda de manera solidaria con la organización política respecto a la multa impuesta por la Oficina Nacional de Procesos Electorales, sin perjuicio de la sanción penal que corresponda, en mérito a lo prescrito en los artículos 356 del Código Penal y 446 del Código Procesal Penal.

Para ello, se propone la modificación de dicha normativa, a fin de que los candidatos que pudieran incurrir en dicha infracción sean procesados por el delito de inducción del voto, con pena privativa de libertad no menor de 2 ni mayor de 3 años y suspensión del derecho de sufragio pasivo por 1 a 2 años, conforme al inciso 3 del artículo 36 del Código Penal, lo cual acarrearía la consiguiente exclusión del candidato del proceso electoral por el Jurado Nacional de Elecciones, en vía de cumplimiento de la sentencia judicial.

Asimismo, se propone la modificación al artículo 446 del Código Procesal Penal a efectos de disponer que el delito de inducción del voto previsto en el artículo 356 del Código Penal, sea conducido a través del proceso inmediato, ello dado la naturaleza del proceso electoral y los limitados tiempos que contempla el calendario electoral, situación que justifica la realización de dicho proceso penal expeditivo en el presente caso.

\section{Conclusiones}

La reforma electoral en nuestro país sigue siendo uno de nuestros mayores pendientes legislativos, y dado que ya nos encontramos a escasos meses para la convocatoria a Elecciones Regionales y Municipales 2018, resulta evidente que las pocas modificaciones que se efectúen antes de convocarse a dicho proceso no podrán abordar los temas más importantes de la reforma.

Sin embargo, desde esta tribuna he querido reflexionar sobre los aspectos que continúan pendientes, y que no deben continuar pendientes con miras a las Elecciones Generales 2021, si queremos contar con un sistema de partidos sólido, y por ende, con candidatos idóneos que puedan constituir buenos gobernantes. 